\title{
Development, applicability and effects of a pilot program of group cognitive-behavioral therapy in Brazilian adolescents with anorexia nervosa
}

\author{
Paula Pegado1, Felipe Alckmin-Carvalho1,2, Danielle Leme1, Francisca Carneiro1, Patrícia Kypriotis', \\ Priscila Camacho ${ }^{1}$, Bacy Fleitlich-BilyK ${ }^{1}$
}

1 Eating Disorders Outpatient and Inpatient Program, Child and Adolescent Psychiatry Division (PROTAD/SEPIA), Department of Psychiatry, Institute of Psychiatry, Universidade de São Paulo (USP), São Paulo, SP, Brazil.

2 Clinical Psychology Program, Institute of Psychology, Universidade de São Paulo (USP), São Paulo, SP, Brazil.

Work conducted in Programa de Atendimento, Ensino e Pesquisa em Transtornos Alimentares na Infância e Adolescência (PROTAD-IPq-HC-FMUSP). Rua Dr. Ovídio Pires de Campos, 785 05403-903 - São Paulo, SP, Brazil

Received: 05/26/2018 - Accepted: 06/05/2018

DOl: 10.1590/0101-60830000000158

\begin{abstract}
Background: Most of the clinical trials involving cognitive-behavioral therapy (CBT) for the treatment of anorexia nervosa (AN) used the individual therapy format, and few have been dedicated to adapting and assessing the effects of the group format. Objectives: To assess the applicability and effects of a group CBT program for Brazilian adolescents with AN. Methods: Open clinical trial with 22 patients with AN divided into an intervention group - IG ( $\mathrm{n}=11$; CBT, psychiatry, nutrition and family psychoeducation- 6 months) and a control group - CG ( $\mathrm{n}=11$; psychiatry, nutrition and family psychoeducation-6 months). Data collected at baseline, at the end of groups and six months after the completion were: weight, height, body mass index and Eating Disorder Examination Questionnaire (EDE-Q) used to assess the severity of AN symptoms. Results: Baseline homogeneous groups, with $91 \%$ adherence in the IG vs. $54 \%$ in the CG $(p=0.05)$. Participants in both groups regained weight and decreased symptoms of eating disorders at the end of groups. Comparing the EDE-Q scores IG presented a statistically significant difference in the restraint subscale of the EDE-Q between the end-of-group and the follow-up ( $p=0.01$ ). Discussion: Group CBT program produced positive effects and was applicable in Brazilian adolescents with AN as an adjuvant to multidisciplinary treatment.
\end{abstract}

Pegado P et al. / Arch Clin Psychiatry. 2018;45(3):57-60

Keywords: Anorexia nervosa, cognitive therapy, adolescents, group therapy.

\section{Introduction}

Anorexia nervosa $(\mathrm{AN})$ is a serious eating disorder, which stands out among psychiatric disorders because it has the highest mortality rate in the general population affected ${ }^{1}$. With typical onset in adolescence, it can affect up to $0.7 \%$ of girls at this phase, while being associated with family, sociocultural and biological risk factors ${ }^{2}$. Better prognoses are usually found in younger patients when treated early in the onset of symptoms ${ }^{2}$.

A recent systematic review ${ }^{3}$ indicated that the most tested model of treatment in childhood and adolescence is family-based therapy $(\mathrm{FBT})^{4}$, which is recommended by the international reference guidelines in mental health, such as those of the National Institute for Health and Clinical Excellence ${ }^{5}$. However, even this treatment modality may not be adequate for all families or patients ${ }^{5}$ and the results are considered to be modest ${ }^{3}$. The authors of the study consider further studies to be needed due to the scarcity of clinical trials, the methodological weaknesses and the different designs tested.

CBT and CBT-E have also been studied as recommended alternatives for the treatment of these patients ${ }^{5}$. One of the basic assumptions of CBT is that individuals develop and maintain basic beliefs throughout their lives that interfere with and influence how they perceive themselves, as well as how they perceive the world around them ${ }^{6}$. In the case of AN patients, weight loss is perceived as an achievement, indicating self-discipline, whereas weight gain is understood as failure and loss of self-control, which seriously interferes with self-esteem ${ }^{7}$. These dysfunctional beliefs about physical shape, weight and eating, function as a risk factor for the establishment of eating pathology and also as maintainers of this condition $^{8}$.

Most of the randomized trials involving CBT and CBT-E for the treatment of AN used the individual therapy format based on the models of Garner et al. ${ }^{\text {, , Garner and Bemis }}{ }^{9}$, as well as the transdiagnostic model ${ }^{10,11}$. Despite it being possible to adapt these model to the group therapy format, few studies have been dedicated to adapting and assessing the effects of the treatment with this configuration.

In particular, in Brazil, where there is a shortage of specialized healthcare services for the treatment of eating disorders (ED) in the Public Healthcare System (SUS - Sistema Único de Saúde) and a waiting list to receive care ${ }^{12}$, the group format could increase the capacity to absorb the existing demand. No study with this objective has been tested in Brazil. The objective of the study is to assess the applicability and effects of a group CBT program developed in a Brazilian teaching hospital for the treatment of AN.

\section{Methods}

\section{Participants}

This is an open clinical trial with AN patients under 18 years of age, that were diagnosed by way of a physician's assessment using the Development and Well-being Assessment (DAWBA), an instrument based on ICD-10 and DSM-IV criteria. Patients that had physical complications that required hospitalization, risk of suicide and/or psychiatric comorbidities prior to AN were excluded from the study.

\section{Assessment instruments}

\section{Eating disorders examination questionnaire - EDE-Q13,14}

Self-reporting questionnaire with 28 questions that aim to assess eating disorder symptoms associated with four subscales: restraint, concern with weight, concern with physical shape and concern with eating. The response options range from 0 to 6 according to the number of days or times in the last four weeks that the patient has 
experienced any of the eating disorder symptoms. The instrument was translated by the coordinators of Protad due to the lack of a version validated for use in Brazil.

\section{Development and Well-Being Assessment - DAWBA}

A set of questionnaires and interviews aimed at the diagnosis of psychiatric disorders in childhood and adolescence, based on ICD10 and DSM-IV criteria ${ }^{15}$.

\section{Procedures}

The sample was divided into two groups: IG, in which the patients received psychiatric, nutritional and family psychoeducational treatment and were submitted to group Cognitive-Behavioral treatment for 6 months; CG, in which the patients were submitted to psychiatric, nutritional, family psychoeducational treatment and to a control group for 6 months in which the patients maintained a food diary.

The study was developed in a teaching hospital and conducted in a Brazilian healthcare service specialized in the treatment of ED in childhood and adolescence. The study-design was approved by the Research Ethics Committee, under CAAE No.: 20524513.8.0000.0068.

The data collected at baseline, at the end and six months after the respective completion were: weight, height, body mass index (BMI) and the Eating Disorder Examination Questionnaire (EDE-Q) used to assess the severity of AN symptoms. The instruments were applied by the psychologists who were not directly involved in the patients' treatment.

\section{CBT Program}

The CBT program was developed based on a model used in the respective mental health department and the models of Garner et al. ${ }^{8}$, as well as the Fairburn transdiagnostic model ${ }^{11}$, used in randomized studies on $\mathrm{CBT}$ and $\mathrm{AN}$, while respecting the adaptation for adolescents and for the group format. The initial model lasted three months, with 12 to 14 non-manualized sessions, with favorable clinical outcomes, despite not yet being tested in clinical trials.

The current program was structured in 24 manualized sessions held in a group setting, lasting 90 minutes, over a six-month period. The group was led by psychotherapists specialized in CBT. Hand-crafted glasses were developed to symbolize the main cognitive distortions present in AN patients, as well as a head band that the adolescents were to use when they identified with thoughts associated with AN.

\section{Data analysis}

Descriptive and inferential statistical analyses were performed using the Statistical Package for Social Science, version 24. The data were processed in the software platform Research Electronic Data Capture ${ }^{16}$ (REDCap). Mean and standard deviation for weight, BMI and EDE-Q scores were calculated for the groups at baseline, at the end-of-groups and at six months of follow-up. The normality of the variables was verified by using the Shapiro-Wilk test.

For the calculation of the difference in the participants' adhesion in each group, the $Z$ Test was used for the proportional difference in independent groups. The Mann-Whitney test (numerical variables) and the chi-square test (categorical variables) were used to assess, at baseline, possible sociodemographic and clinical differences between the IG and CG. Differences in baseline $v s$. end of group and end $v s$. follow-up, within each group, were assessed by the Wilcoxon test. Differences in performance between the groups at the end and in follow-up were assessed by using a nonparametric repeated-measures analysis of variance with two factors. A probability level of $95 \%$ ( $\mathrm{p} \leq$ 0.05 ) was adopted for the rejection of null hypotheses.

Being adopted as a complete remission criterion was: zero score in the EDE-Q and weight recovery according to the percentile expected for gender and age, between 25 and 75 (or return to the percentile that the patient presented before the ED, except for the cases of prior obesity). Partial remission: patients who recovered weight but who still had eating psychopathology indicators, or patients weighing below the 25 th percentile or reported to be underweight before the ED, while demonstrating improvement in eating psychopathology indicators.

\section{Results}

The IG and CG were compared at baseline, in order to assess the homogeneity of distribution of the participants. Regarding sociodemographic data in terms of socioeconomic status, family type and ethnicity, there were no statistically significant differences between the groups. No statistically significant differences were found in the clinical variables investigated. Table 1 shows the results for the comparisons between the groups.

\section{Adherence to treatment}

In the IG, of the initial 11 patients in the group, $10(91 \%)$ remained until the end. In the CG, of the initial 11 patients, 6 (54\%) patients remained until the end, with this difference being considered statistically significant $(\mathrm{Z}=1.91, \mathrm{p}=0.05)$.

\section{Remission at the end of groups}

At the end, 2 (20\%) IG patients presented complete remission of symptoms vs. $1(16.7 \%)$ of the CG $(Z=0.16, p=0.86)$. Partial remission occurred in $8(80 \%)$ IG patients vs. $5(83.3 \%)$ in the CG $(\mathrm{Z}=-0.17, \mathrm{p}=0.86)$. At the end in the IG, $10(100 \%)$ patients were between the $25-50$ percentiles or higher vs. $6(100 \%)$ in the CG.

\section{Remission at follow-up}

In the follow-up of the IG, 3 (30\%) presented complete remission vs. $1(16.6 \%)$ of the CG $(Z=0.59, p=0.54)$. At this stage, $7(70 \%)$ from the IG presented partial remission vs. $5(83.3 \%)$ from the CG $(\mathrm{Z}=-0.60, \mathrm{p}=0.54)$. At the follow-up stage, $7(70 \%)$ participants were in the $25-50$ percentiles vs. $6(100 \%)$ from the CG $(Z=-1.48$, $\mathrm{p}=0.13$ ) (Table 2).

Table 1. Comparison of clinical characteristics of the IG and $C G$ at baseline

\begin{tabular}{|c|c|c|c|c|c|}
\hline \multirow[b]{2}{*}{ Variables } & \multicolumn{2}{|c|}{$\begin{array}{l}\text { Intervention Group } \\
(I G)(N=10)\end{array}$} & \multicolumn{2}{|c|}{$\begin{array}{l}\text { Control Group (CG) } \\
(\mathrm{N}=06)\end{array}$} & \multirow{2}{*}{$\begin{array}{c}\text { Mann- } \\
\text { Whitney } \\
\text { p-value }\end{array}$} \\
\hline & Mean & SD & Mean & SD & \\
\hline Years of age & 14.80 & 1.28 & 14.00 & 1.69 & 0.175 \\
\hline $\begin{array}{l}\text { Duration of symptoms } \\
\text { (months) }\end{array}$ & 12.30 & 6.39 & 6.83 & 1.47 & 0.127 \\
\hline Initial weight (kg) & 46.40 & 5.2 & 44.10 & 7.61 & 0.828 \\
\hline Initial height (cm) & 162.1 & 5.6 & 157.8 & 4.8 & 0.158 \\
\hline Initial BMI $\left(\mathrm{kg} / \mathrm{m}^{2}\right)$ & 17.62 & 1.51 & 17.56 & 2.22 & 0.745 \\
\hline Weight loss (kg) & 9.10 & 6.47 & 10.10 & 3.46 & 0.581 \\
\hline EDE-q (Global) & 3.25 & 1.83 & 4.56 & 0.75 & 0.159 \\
\hline EDE-q (Restraint) & 3.20 & 1.94 & 4.60 & 0.82 & 0.230 \\
\hline EDE-q (Weight Concern) & 3.48 & 1.95 & 4.73 & 1.00 & 0.210 \\
\hline EDE-q (Shape Concern) & 3.76 & 1.81 & 5.12 & 0.81 & 0.127 \\
\hline \multirow[t]{2}{*}{ EDE-q (Eating Concern) } & 2.56 & 1.92 & 3.80 & 1.33 & 0.276 \\
\hline & \multicolumn{2}{|c|}{$N(\%)$} & $\mathrm{N}(\%)$ & \multicolumn{2}{|c|}{$\begin{array}{c}\text { Pvalue } \\
\text { Chi-square }\end{array}$} \\
\hline Depression & \multicolumn{2}{|c|}{$2(20 \%)$} & $2(33.3 \%)$ & \multicolumn{2}{|c|}{0.551} \\
\hline Anxiety & \multicolumn{2}{|c|}{$3(30 \%)$} & $3(50 \%)$ & \multicolumn{2}{|c|}{0.424} \\
\hline Amenorrhea & \multicolumn{2}{|c|}{$7(70 \%)$} & $5(83.33 \%)$ & \multicolumn{2}{|c|}{0.792} \\
\hline
\end{tabular}

Source: study data 
Table 2. Results of assessments performed between the baseline, the end and follow-up for the intervention and control groups

\begin{tabular}{|c|c|c|c|c|c|c|c|c|c|c|c|c|}
\hline \multirow{3}{*}{ Variables } & \multicolumn{3}{|c|}{$\begin{array}{l}\text { Intervention Group (IG) } \\
\qquad(n=10)\end{array}$} & \multicolumn{3}{|c|}{$\begin{array}{l}\text { Control Group (CG) } \\
\qquad(\mathrm{n}=06)\end{array}$} & IG & CG & IG & CG & \multirow{2}{*}{\begin{tabular}{|c|}
$\begin{array}{c}\text { Interaction } \\
\text { IG vs. CG }\end{array}$ \\
T0-T1 \\
\end{tabular}} & \multirow{2}{*}{$\begin{array}{c}\text { Interaction } \\
\text { IG vs. CG } \\
\text { T1-T2 }\end{array}$} \\
\hline & Baseline (TO) & End (T1) & $\begin{array}{l}\text { Follow-up } \\
\text { (T2) }\end{array}$ & Baseline (TO) & End (T1) & $\begin{array}{l}\text { Follow-up } \\
\text { (T2) }\end{array}$ & \multicolumn{2}{|c|}{ T0-T1 } & \multicolumn{2}{|c|}{$\mathrm{T} 1-\mathrm{T} 2$} & & \\
\hline & $\mathrm{M}(\mathrm{SD})$ & $\mathrm{M}(\mathrm{SD})$ & $\mathrm{M}(\mathrm{SD})$ & $\mathrm{M}(\mathrm{SD})$ & $\mathrm{M}(\mathrm{SD})$ & $M(S D)$ & $\mathrm{P}^{*}$ & $P^{*}$ & $\mathrm{P}^{*}$ & $P^{*}$ & $\mathrm{P}^{* *}$ & $P^{* *}$ \\
\hline Weight (kg) & $46.3(5.2)$ & $52.2(5.7)$ & $52.9(7.5)$ & $44.0(7.6)$ & $51.5(9.2)$ & $53.5(10.8)$ & 0.005 & 0.028 & 0.575 & 0.028 & 0.403 & 0.280 \\
\hline $\mathrm{BMI}(\mathrm{kg})$ & $17.62(1.51)$ & $19.74(1.27)$ & $19.95(2.00)$ & $17.56(2.22)$ & 20.34 (2.59) & $20.96(3.27)$ & 0.005 & 0.028 & 0.508 & 0.028 & 0.386 & 0.112 \\
\hline EDE 0 Global & $3.25(1.83)$ & $1.14(1.53)$ & $0.54(1.38)$ & $4.56(0.75)$ & $1.74(1.57)$ & $1.14(1.67)$ & 0.007 & 0.046 & 0.012 & 0.345 & 0.561 & 0.409 \\
\hline \multicolumn{13}{|l|}{ Subscales } \\
\hline Restraint & $3.20(1.94)$ & $0.56(0.94)$ & $0.30(0.81)$ & $4.60(0.82)$ & $0.70(1.04)$ & $0.93(1.48)$ & 0.007 & 0.028 & 0.026 & 0.414 & 0.234 & 0.012 \\
\hline $\begin{array}{l}\text { Concern with } \\
\text { weight }\end{array}$ & $3.48(1.95)$ & $1.32(1.94)$ & $0.70(1.80)$ & $4.73(1.00)$ & $2.10(1.64)$ & 1.30 (1.97) & 0.014 & 0.028 & 0.072 & 0.344 & 0.591 & 0.573 \\
\hline $\begin{array}{l}\text { Concern with } \\
\text { eating }\end{array}$ & $2.56(1.92)$ & $0.86(1.20)$ & $0.44(1.06)$ & $3.8(1.33)$ & $1.46(1.46)$ & $0.73(1.11)$ & 0.018 & 0.074 & 0.016 & 0.131 & 0.585 & 0.952 \\
\hline $\begin{array}{l}\text { Concern with } \\
\text { shape }\end{array}$ & $3.76(1.81)$ & $1.83(2.21)$ & $0.75(1.86)$ & $5.12(0.81)$ & $2.71(2.60)$ & $1.62(2.22)$ & 0.036 & 0.075 & 0.018 & 0.345 & 0.678 & 0.248 \\
\hline
\end{tabular}

Intervention Group = (Cognitive Behavioral Therapy + psychiatry, nutrition and family psychoeducation), Control group = (psychiatry, nutrition and family psychoeducation). BMI = body mass index EDE- 0 = Eating Disorder Examination Questionnaire

* Wilcoxon test used to compare the means of each variable between the baseline and the end of the IG and CG and between the end and the follow-up.

** Wald test for the effect of interaction, to assess the difference in performance between the intervention and control groups between the baseline and the end, and between the end-of-groups and the follow-up.

$P \leq 0.05$.

Source: study data.

\section{Intragroup analysis}

There was a statistically significant difference in all variables analyzed after the IG. Mean weight gain and change in BMI remained the same in the follow-up. With the exception of the weight concern subscale, all the variables investigated by the EDE-Q improved in the follow-up.

In the CG, at the end, significant differences in weight, BMI and in all variables assessed by EDE-Q were also found, with the exception of eating and shape concern subscales. In the follow-up, mean weight and BMI in the CG were statistically greater than those after the intervention. No significant difference was found in the variables of the EDE-Q.

\section{Intergroup analysis}

At the end of groups there was no statistically significant difference in any of the variables investigated. In the follow-up, despite the EDE-Q restraint subscale being the only subscale presenting a statistically significant difference in the comparison between IG and CG (W = $6.19, p=0.012$ ), the analysis of the means of all the EDE-Q scales were lower in the IG, which indicates a lower severity of ED symptoms.

\section{Discussion}

The results of this clinical trial demonstrated that the group CBT program is applicable, while having tools that were well accepted by the adolescents and is possibly responsible for the patients' improved treatment adherence in comparison with the CG. These results are in line with a recent systematic review that assessed the efficacy and adherence of CBT in 16 studies $^{17}$.

In the present study, complete remission was observed in $20 \%$ of patients at the end of the group therapy and in 30\% at follow-up. Similar results were found in another study ${ }^{18}$, which found complete remission in $19 \%$ at the end of treatment and 33\% in the second year of follow-up. The clinical trial ${ }^{19}$ found slightly higher complete remission rates: $30 \%$ at the end of treatment and $33 \%$ at three years of follow-up.

Partial remission was achieved by $80 \%$ of patients at the endof-group in the IG and by $70 \%$ at follow-up. It was not possible to compare these results with those of other studies due to lack of data or methodological differences.
In this study, the IG patients presented a mean weight gain and improvement in the means for eating symptoms at the end of group and at follow-up. This result is in line with previous studies ${ }^{18,20-22}$ and is a preliminary indicator of the positive effects of multidisciplinary treatment using CBT.

The majority of IG patients maintained their respective weight gain between the end-of-group and follow-up, except those who were discharged immediately following the end-of-group. Despite presenting worse results in comparison with those observed in the CG in terms of regained weight, the reduction of ED symptoms assessed by the EDE-Q was more expressive (in descriptive terms) in the IG, while showing a statistical difference in the comparison between the groups in the subscale which assesses restraint, in the follow-up. A similar result, with regard to the reduction of symptoms, was presented in a study ${ }^{23}$ that compared CBT with Psychodynamic Therapy.

The CG did not present a significant statistical difference in the improvement of the eating symptoms between the end-of-group and the follow-up; whereby the intervention group continued to maintain improvement in three of the four subscales of the EDE-Q: restraint, eating concern and shape concern. The only subscale that did not present a significant statistical difference between the endof-group and the follow-up in the intervention group was related to the weight concern.

As pointed out in a systematic review ${ }^{17}, \mathrm{CBT}$ appears to be useful in preventing the risk of relapse in the future and the fact that IG demonstrated continued improvement in symptoms between the end-of-group and follow-up may support this observation, for example, the study by Carter et al. ${ }^{24}$ who observed, in patients treated with CBT, the permanence without eating symptoms for a longer period of time.

Despite a weight gain being found in both groups, changes in dysfunctional beliefs regarding body, shape and eating were more visible in the IG, as assessed through the subscales of the EDE-Q. CBT in the treatment of EDs aims to modify the mechanisms that maintain the eating psychopathology ${ }^{11}$. Since dysfunctional beliefs are risk factors for engaging the diet and weight loss, which in turn are triggers for the reappearance of ED, it is therefore necessary to address these issues. This measure is indicative of better long-term prognostics 24 . 
This is the first Brazilian clinical trial with a control group to assess the effects of group CBT in the treatment of AN in adolescence. Therefore, this is a pioneering study, in that it presents a pilot program of group CBT adapted for adolescents with AN, while being manualized and capable of being replicated. The proposed objectives were achieved, however, some methodological weaknesses limit the significance of the findings. Although the number of sessions for each group was the same, the period of treatment offered to each patient varied between groups. In addition, because the CG did not receive psychotherapeutic intervention and because of the impossibility of blinding in the study, the professionals may have unintentionally offered more attention to these patients. In addition, there was no control for psychotropic medication for the symptoms of psychiatric comorbidities in the two groups, nor for the possible psychotherapeutic interventions that the patients of the CG may have undergone during the treatment, which translates into a threat to the internal validity of the study. As a threat to external validity, the reduced sample size is noted, which makes it difficult to generalize the results.

It is expected that the present study will stimulate additional scientific productions on the theme of ED in childhood and adolescence, in Brazil. For future studies we recommend replications with larger samples, a clinical trial in the Brazilian population with longer follow-up periods to better assess the effects of CBT in the treatment of adolescents with $\mathrm{AN}$, and comparison between individual and group formats.

The results suggest that the group CBT program produced positive effects and was applicable in Brazilian adolescents with AN as an adjuvant to multidisciplinary treatment aimed at improving adherence and diminishing the risk of relapse.

\section{Brazilian Clinical Trials Registry (ReBec)}

RBR-4dpths.

\section{Acknowledgments}

The authors are grateful to the entire staff of the Eating Disorders Outpatient and Inpatient Program - Child and Adolescent Psychiatry Division (PROTAD/SEPIA), Institute of Psychiatry, Universidade de São Paulo - that contributed to the conducting of this study. The authors would like to thank patients and families involved for trusting and sharing their experiences making this study possible.

\section{Conflict of interest}

Nothing to declare.

\section{References}

1. Arcelus J, Mitchell AJ, Wales J, Nielsen S. Mortality rates in patients with anorexia nervosa and other eating disorders: a meta-analysis of 36 studies. Arch Gen Psychiatry. 2011;68(7):724-31.

2. Fitzpatrick KK, Lock J. Anorexia nervosa. BMJ Clin Evid. 2011;2011. pii: 1011.

3. Alckmin-Carvalho F, Bergamo JV, Cobelo AW, Fabbri A, Pinzon VD, Melo MHDS. Evidence-based psychotherapy for treatment of anorexia nervosa in children and adolescents: systematic review. Arch Clin Psychiatry. 2018;45(2):41-8.
4. Lock J, Le Grange D. Treatment manual for anorexia nervosa: A familybased approach. Guilford Publications; 2015.

5. National Institute for Health and Clinical Excellence. Eating disorders: recognition and treatment NICE guideline NG69. 2017. Available from: https://www.nice.org.uk/guidance/ng69/chapter/Recommendations. Acessed on: 8 Nov. 2017.

6. Beck JS. Teoria Cognitiva: Teoria e Prática. Porto Alegre: Artes Médicas; 1997.

7. American Psychiatric Association. DSM-5: Manual Diagnóstico e Estatístico de Transtornos Mentais. 5 ed. Porto Alegre: Artmed; 2014.

8. Garner DM, Vitousek KM, Pike KM. Cognitive-behavioral therapy for anorexia nervosa. In: Garner DM, Garfinkel PE, editors. Handbook for Treatment of Eating Disorders. New York: Guilford; 1997. p. 94-144.

9. Garner DM, Bemis KM. Cognitive therapy for anorexia nervosa. In: GD M, Garfinkel PE, editors. Handbook of Psychotherapy for Anorexia Nervosa and Bulimia. New York: Guilford; 1985. p. 107-46.

10. Fairburn CG, Cooper Z, Shafran R. Cognitive behaviour therapy for eating disorders: a "transdiagnostic" theory and treatment. Behav Res Ther. 2003;41(5):509-28.

11. Fairburn CG. Behavior Therapy and Eating Disorders. New York: The Guilford Press; 2008.

12. Moya T, Fleitlich-Bilyk B. Waiting lists for treatment of eating disorders in childhood and adolescence. Rev Bras Psiquiatr. 2003;25(4):259-60.

13. Fairburn CG, Beglin SJ. Assessment of eating disorders: interview or self-report questionnaire? Int J Eat Disord. 1994;16(4):363-70.

14. Fairburn, CG. Eating Disorder Examination Questionnaire (EDE-Q 6.0). In: Fairburn CG (ed). Cognitive Behavior Therapy and Eating Disorders. New York: Guilford Press; 2008. p. 309-13.

15. Goodman R, Ford T, Richards H, Gatward R, Meltzer H. The Development and Well-Being Assessment: description and initial validation of an integrated assessment of child and adolescent psychopathology. J Child Psychol Psychiatry. 2000;41(5):645-55.

16. Harris PA, Taylor R, Thielke R, Payne J, Gonzalez N, Conde JG. Research electronic data capture (REDCap)--a metadata-driven methodology and workflow process for providing translational research informatics support. J Biomed Inform. 2009;42(2):377-81.

17. Galsworthy-Francis L, Allan S. Cognitive Behavioural Therapy for anorexia nervosa: a systematic review. Clin Psychol Rev. 2014;34(1):54-72.

18. Gowers SG, Clark A, Roberts C, Griffiths A, Edwards V, Bryan C, et al. Clinical effectiveness of treatments for anorexia nervosa in adolescents: randomised controlled trial. Br J Psychiatry. 2007;191:427-35.

19. Ricca V, Castellini G, Lo Sauro C, Mannucci E, Ravaldi C, Rotella F, et al. Cognitive-behavioral therapy for threshold and subthreshold anorexia nervosa: a three-year follow-up study. Psychother Psychosom. 2010;79(4):238-48.

20. McIntosh VV, Jordan J, Carter FA, Luty SE, McKenzie JM, Bulik CM, et al. Three psychotherapies for anorexia nervosa: a randomized, controlled trial. Am J Psychiatry. 2005;162(4):741-7.

21. Fairburn CG, Cooper Z, Doll HA, O'Connor ME, Palmer RL, Dalle Grave R. Enhanced cognitive behaviour therapy for adults with anorexia nervosa: a UK-Italy study. Behav Res Ther. 2013;51(1):R2-8.

22. Dalle Grave R, Calugi S, Doll HA, Fairburn CG. Enhanced cognitive behaviour therapy for adolescents with anorexia nervosa: an alternative to family therapy? Behav Res Ther. 2013;51(1):R9-12.

23. Zipfel LS, Wild B, Gross G, Friederich HC, Teufel M, Schellberg D, et al. Focal psychodynamic therapy, cognitive behaviour therapy, and optimised treatment as usual in outpatients with anorexia nervosa (ANTOP study): randomised controlled trial. Lancet 2014;383(9912):127-37.

24. Carter J, McFarlane T, Bewell C, Olmsted M, Woodside D, Kaplan A, Crosby R. Maintenance treatment for anorexia nervosa: a comparison of cognitive behavior therapy and treatment as usual. Int J Eat Disord. 2009;42(3):202-07. 